\section{ETNIA AYAMÁN. VISIÓN ARTÍSTICA CREATIVA DE SUS “TURAS”}

Hilda Rojas

Sonia Urbano

UPEL-IPB

Recibido: $14-03-06$

Aprobado: 25-05-06

\section{RESUMEN}

El propósito del estudio describe en su connotación artística creativa, el baile "Las Turas” de la etnia Ayamán, ubicada en el Cerro Moroturo, municipio Urdaneta, estado Lara. La investigación pertenece al paradigma cualitativo bajo el enfoque etnográfico caracterizando el estilo de vida grupal manifiesto en el convivir diario, constituyendo una entidad de interrelaciones reguladas por tradiciones, estilos de vida, identidades religiosas y con la naturaleza, principios..., tales como: creencias heredadas de generación en generación, elementos espirituales provenientes de dioses, espíritus, María Santísima; significado y contacto con el entorno natural, valores, normas de convivencia y respeto hacia su baile "Las Turas". Como procedimiento se realizó la negociación de entrada recolectando la información a través de las técnicas: entrevistas a profundidad con informantes clave, observación participativa y notas de campo. El análisis de la información se presentó en categorías y subcategorías conceptualizadas, y propias del estudio.

Palabras clave: etnia Ayamán, visión artística creativa, las Turas.

\section{AYAMAN ETHNIC GROUP AND THE ARTISTIC VISION OF ITS TURAS}

\section{Abstract}

This study describes, from a creative artistic point of view, the dance "Las Turas" of the Ayamán ethnic group, located in Cerro Moroturo, Urdaneta County, in Lara state. It is a qualitative investigation under the ethnographic approach. The everyday group family life, which is composed of inter relational entities established by traditions, lifestyles, religious identities, among others, is characterized by the researchers. There is also the description of the relations established with nature and various principles, such as inherited beliefs from generation to generation, godly spiritual elements, Maria Santisima; meaning and contact with the natural surroundings, values, rules for a living and respect toward the dance "Las Turas." In order to obtain information, negotiation was required. The techniques to collect the data were extended interviews with key informants, participative observation, and note-taking. The analysis of data was presented in conceptualized categories and subcategories.

Keywords: Ayamán ethnic group, creative artistic vision, the Turas

\section{INTRODUCCIÓN}

Hacia el Cerro Moroturo un silencio ancestral se desborda desdibujándose junto al viento gigantescas arboledas, retumbando la cadencia codiciosa bajo la creación de dioses. En la circunscripción del entorno se encuentra asentada la etnia “Ayamán” conocida por sus dotes artísticos manifestado en el baile "Las Turas".

Adentrarse en esta etnia y su esencia, implica conocer su legendaria cultura como folclore patrimonio cultural de la humanidad, así como retornar a raíces propias de una nación.

El municipio Urdaneta donde se ubica el Cerro Moroturo limita con el estado Falcón, hacia el lindero norte del estado Lara en el trayecto que comprende la desembocadura de la quebrada Carapa del río Tocuyo, donde se encuentra el punto de la serranía Buena Vista, bajo el nacimiento del río Pedregal. Limita con el municipio Torres por el suroeste, hacia el lindero norte de dicho municipio que parte de la cabecera del río Pedregal terminando en lo alto del Cerro Grande. Hacia el sureste se dirige a los municipios Iribarren y Crespo por su origen del Cerro Grande para llegar al Cerro "El Olivo" siguiendo la línea por la desembocadura de la quebrada "El Centavo" en el río Urama.

El pueblo Moroturo está considerado punto geográfico importante en la agricultura y ganadería del estado Lara. El caserío Cerro de Moroturo es un 
lugar mitológico y legendario donde se establecen personas con rasgos ayamanes.

El baile "Las Turas” que se realiza en esta localidad, según sus actores, ocurre desde el momento en el cual la Virgen María se pasea con un niño en los brazos. Esta danza se realiza en homenaje a la cosecha de maíz, a los dioses que proporcionan sus alimentos, y a los espíritus desencarnados. La manifestación artística del baile se entrecruza con elementos colectivos, en búsqueda de unidad grupal, afianzando los sones musicales en forma repetitiva. Los movimientos, mezcla de rituales para los espíritus, consiguen mezclarse con silencios, ofrendas y brindis en altares particulares mágicos.

\section{Propósito de la investigación}

Describir en su connotación artística creativa, el baile "Las Turas" de la etnia Ayamán ubicada en el Cerro Moroturo, municipio Urdaneta, estado Lara.

\section{INHERENCIA INTERACTIVA ETNOGRÁFICA}

La Etnografía, se considera un enfoque de investigación que estudia los grupos sociales, su organización, cultura, política, sistemas y estilos de vida de una comunidad, estado o país, al describir fenómenos de forma global en su contexto natural, recorriendo los significados y significancias de la información recopilada desde los informantes clave.

Según Martínez (2000), un estudio etnográfico se apoya en la convicción de que las tradiciones, roles, valores y normas del ambiente donde se vive se van internalizando poco a poco, y generan regularidad que pueden explicar la conducta individual y de grupo en forma adecuada.

El objetivo inmediato de un estudio etnográfico es crear una imagen realista y fiel del grupo estudiado, pero su intención y mira más lejana es contribuir a la comprensión de grupos poblacionales más amplios que tienen características similares. La ventaja que tiene la investigación etnográfica es la flexibilidad y apertura que le otorga su orientación naturalista y fenomenológica.

Sandín Esteban (2003) sostiene que los estudios etnográficos no deben deformar, distorsionar o perturbar la verdadera realidad del fenómeno abordado. Tampoco se deben descontextualizar los datos aislándolos de su contorno natural. Todo esto exige que la información sea recogida en la forma más completa posible con detalles, matices y aspectos peculiares sobre lenguaje, vestidos, costumbres

\section{Informantes y Escenario}

La etnia Ayamán tiene sus orígenes en el siglo XVI donde un poblado se adentró en sus tradiciones y respeto por la naturaleza. El grupo aborigen localizado en el Cerro de Moroturo-estado Lara, se ubica en una gran montaña a la altura de $850 \mathrm{mts}$ sobre el nivel del mar. Su nombre se deriva de "Morotutu", en honor a un indio que luchó en contra de los españoles. El Cerro Moroturo está cargado de leyendas y en él habitan aproximadamente 290 personas de herencia Ayamán. Los mismos trabajan su colectivo en pro de la etnia, donde cada uno tiene responsabilidades que deben cumplir desde muy temprano. Los hombres despiertan con el rocío y comienzan a pastizar el ganado, las mujeres trabajan en pequeños conucos para luego cocinar, los ancianos son respetados y obedecidos por los demás miembros del caserío, y no realizan muchas labores puesto que son sinónimo de una sabiduría resguardada por sus años de existencia.

En el centro de la comunidad existe un espacio donde vive la familia Perozo, lugar donde convive toda la comunidad de Moroturo, espacio determinado para realizar el baile aborigen "Las Turas". La familia Perozo está encargada de organizar dicho baile. Las Turas guarda un profundo significado espiritual, natural y humano. A través del mismo se adoran los dioses para obtener una buena cosecha de maíz, para bendecir la tierra y lograr que la lluvia llegue a tiempo para conseguir una tierra fértil. Dentro de su peculiar música se guarda la esencia del hombre-tierra-agua a fin de 
mantener la vida de los seres. Las Turas comienza con el ocaso, continua con el fresco de la noche, se aviva con la fría madrugada y finaliza con el trasnochar de músicos, bailadores y visitantes, los cuales se regocijan mutuamente a través de los ojos de los dioses que sintieron lo grato de las ofrendas brindadas.

\section{Solicitudes de entrada.}

Según Martinez (2004) el etnógrafo es sensible en cuanto a la manera de introducirse en un ambiente, además establece con cuidado el rol que pueda facilitarle el acopio de información. El investigador tiene que recurrir a estrategias variadas para lograr sus fines: exponer sus motivos, asegurar un pleno respeto a la confidencialidad, al secreto, y obtener permiso de las autoridades de mayor jerarquía para lograr con éxito la investigación.

La entrada en el grupo de estudio se realizó de la siguiente manera:

En el remanso bullicioso de aves cantarinas una transparente mañana subíamos al Cerro Moroturo tratando de conocer a la reina del baile "Las Turas”, la señora María Perozo. Preguntando a los lugareños, llegamos a la última casa del Cerro cubierta externamente por gigantescas arboledas. La sencillez del tibio hogar remueve nuestros inquietos intereses investigativos frente al encuentro certero de la familia Perozo, sus animales domésticos y su naturaleza festiva. La peculiar familia abrió con beneplácito las puertas de su casa. Una señora menuda de avanzada edad se divisa a lo lejos, corriendo, su nieta grita: - abuela, abuela; son del Pedagógico, vienen hablar contigo. La abuela se acerca y amablemente pregunta: - ¿Qué los trae por aquí? - Queríamos saber si podríamos conocer un poco más sobre su baile: "Las Turas”. ¡Claro! ¡Pasen adelante! Mientras se sonreía y sin pedírselo ofreció a los investigadores un vaso con agua, y expresó: - Se ven muy cansados. Siempre nos visitan muchas personas. Mientras tanto, una joven traía unos café. Con este hermoso clima humano, cómodos, los visitantes, comenzamos a realizar algunas preguntas. La señora María complacida dijo: - Puedo responder lo que ustedes me pidan. Posteriormente sacó de un baúl unos cuadernos de talleres que se habían realizado sobre "Las Turas" y entregó a los investigadores el paquete de hojas, diciendo: - Esto les puede servir. Luego, se dio comienzo a la entrevista, (los monos se mecían en los árboles tras el murmullo caliente del sol), y se vislumbrava un señor que venía de traer las vacas, cansado y sudado. La señora María le dice- Son de la universidad, y el señor expresa:

- Con permiso, voy a tender el chinchorro. Comenzamos entonces a hacer las preguntas: - Señora María: - ¿Cuándo nace el baile de "Las Turas”?. Bueno, desde que empezó que empezamos nosotros aquí porque eso mire cómo será de anticuáo que cuando la Virgen María andaba con el niño en brazos, ya existía el baile de "Las Turas", por eso decimos: el baile de María Santísima.

- ¿Qué quiere decir este baile? Pues se hace en homenaje a la cosecha y a nuestros dioses que nos dan nuestros alimentos y que es el baile de los espíritus. Se hace finalizando en el mes de julio y septiembre siempre que sea día sábado para que asistan todas las personas que quieran venir.

\section{-¿Sí, en especial el día sábado?, preguntamos nosotros.}

Sí, puede ser cualquier día, pero nosotros lo hacemos porque el que vaya a venir que esté trabajando pueda venir, y son bien recibidos, todo el que tenga gusto y el que tenga gusto de colaborar también.

$-\succsim$ Y quienes son los que bailan?

Con lo nosotro con lo puede hace ahí que chévere.

- ¿O sea que es un baile colectivo?

Sí, es un baile colectivo, la unidad donde está la unidad de todos los que habitan acá en el sector Las Turas tienen los sones.

Ya finalizada la entrevista, le preguntamos a la señora María: 
-¿Podemos tomar unas fotos?

Con voz amable respondió.

- Esperen que me voy a bañar, quiero salir limpia porque antes de que llegaran estaba alimentando los marranos.

Al cabo de unos minutos, la Reina María apareció con un vestido azul y su corona que le acredita como Reina. Se dispuso a llevarnos al altar para pasearnos por los misterios religiosos del pueblo ayamán; ahí estaban sus creencias y los instrumentos utilizados para el baile. Al salir de allí nos indicó que bajáramos al bosque donde se encuentra el Palacio Ayamán, advirtiéndonos que llegáramos hablando porque - "es mediodía y los espíritus están en todos lados”.

Al entrar en el Palacio, dijo: - deben dar la vuelta, no pueden salir por donde entraron, no olviden "precinarse" al subir.

Cuando llegamos de vuelta nuevamente a la casa de la familia Perozo, la Reina María nos esperaba para conocer de nuestras impresiones y ver si los espíritus de sus ancestros nos habían recibido con bien. A los pocos segundos, su nuera, una simpática joven nos dijo: - Está servido, pueden venir a comer.

Terminando el almuerzo nos dijo: - Pueden regresar el próximo miércoles para el encuentro de los “Ayamanes”, que Dios los lleve con bien.

\section{Cosmovisión en la Creática de “Las Turas”}

El espectáculo danzístico se inicia a una hora específica, 5:00 pm. Se preparan para recibir en el baile la cacería de animales, lo cual ocurre en una capilla donde son presentadas todas las ofrendas, como por ejemplo, las sobras del maíz, las frutas, bebidas diversas... Posteriormente los "tureros" al son de un mismo ritmo musical que interpretan, colocan en el portal de la capilla lo que ofrendan. A partir de este último momento comienzan los siete sones programados para hacer la repartición de alimentos y bebidas después de ofrendadas. Se inician entonces los sones, de derecha a izquierda, y en sentido contrario a las agujas del reloj, en el patio central. El "son de la ceremonia" es conducido por la Reina, el capataz y cinco músicos. El "son del Gonzalito" es ofrecido en esencia al pájaro Gonzalito, el cual despierta en las mañanas a los conuqueros para el inicio de sus faenas diarias. Con su ejemplo, este pequeño pájaro azul pasa la tarde entera recogiendo con su pico pedazos de hojas, polvillos, y diminutas cosas de la tierra. Estos pasajes del pájaro motivan los movimientos cada vez más circulares del son, los ritmos impregnados ahora de ingenuidad y ternura, se cobijan en cadencias, producto de pequeños silencios musicales y ritmos entrecortados. Continúa el "son de la hormiga" para lo cual traen una porción de la cosecha de maíz, toman una hojita de cualquier árbol de la montaña y lo pisan para que la hormiga no se coma las ganancias obtenidas de la venta del maíz. Le sigue el "llorío del agua". En danzas continuas, se recoge el agua destinada para la siembra, lo cual se repite hasta parecer alcanzar lo profundo de lagunas fértiles. El "son de la paloma" se efectúa a la siete de la mañana porque la mañana ofrece cortésmente su sombra. Para bailarla se marcan las sombras producidas por el baile. Se celebra al amanecer. El variquí es otro son que consiste en moler piedras no tan rocosas, las cuales se deshacen en poca agua, la mezcla ya elaborada, al ritmo de la danza, se va aplicando en forma de cruz en la frente o brazo derecho de todos los presentes. Otro de los sones, es el llamado "el Turpial y el Murciélago", los bailadores fingen ser murciélagos, tocan los tambores tureros invitando con ellos a un baile general, donde nadie se queda dormido y participa con enorme alegría de los movimientos de su cuerpo.

Los siete sones mencionados se acompañan del instrumento "Turas", además de los llamados "cachos". Hay dos clases de Turas, la Tura macho 
que tiene cuatro orificios y la Tura hembra que tiene tres. Los "Cachos" de mataca hechos de venado, pueden ser grandes, medianos y pequeños. Las Turas están elaboradas con una especie de sisal carrizo, llamado "tura" de donde se origina el nombre de estos tambores.

Los dioses de los bailes en esta cultura no se mencionan, pero están implícitos en cada faena manifiesta a través del baile. Los sinsabores se han alejado de sus espíritus predominando la alegría, el regocijo y la celebración cuando el día de Las Turas ha llegado. Hasta repentinos presagios de felicidad acontecen en la fuente, desarrollo y finalización de los sones. Una reina, mujer, tierra, madre, creadora... domina el trono en señal de victoria, longevidad permanente de frutos juveniles, triunfo de una etnia que se atribuye el gozo de saberse reconocida en el baile que la distingue con su elocuencia cantora, corporal e instrumental. Lo femenino aunado a lo masculino erige dos etnias que se nutren, dos reinas, los capataces, la reina de Moroturo y la reina de San Pedro de Mapararí, todos, juntan fuerzas energéticas para avanzar hacia el futuro. Dos capataces de las mismas regiones recogen los sones, quienes visten ropas comunes del diario vivir, participando los niños, niñas, mujeres, hombres jóvenes y adultos propios de la etnia, además de todos los presentes que muchas veces son tureros de San Pedro de Mapararí del estado Falcón, con quienes comparten sus bailes, costumbres y tradiciones, enriqueciendo sus legados, propios de la etnia. Sus expresiones corporales y faciales van volviéndose cada vez más creativas a medida que el baile se desenvuelve. Se organizan en forma circular de manera indistinta vez por vez hacia la derecha y la izquierda, los golpes de zapateo con rápidos movimientos deberán llevar el ritmo de "Las Turas”.

Llama la atención la variedad de comidas y bebidas derivadas del maíz que se brindan a María Santísima, al indio Paracatomi, a Dios, a los ancestros y a los espíritus protectores. Durante la danza presentan producto de su cosecha, torta de maíz tierno, mazamorra, carato fermentado, y chicha criolla. En la ceremonia rezan una salve especial diferente a la de la iglesia católica para cumplir las promesas y evitar las penas de los ancestros, deberán tocar un son antes de comenzar el rosario.
Celebrar "Las Turas" complace el alma de los "tureros", rindiéndole honores a su vida, los toques ocurridos en los altares como tribunas entrelazadas con anécdotas indígenas recogidas de los ancestros, nacen en el soslayo épico de animales a quienes se les atribuyen hazañas importantes del nacimiento del maíz, como la ardilla enviada por los dioses "que se puso prensadita aquí" y le dijo: "de estas dos mazorquitas va a sembrar un poquito en cada esquina y va a ver que se le va a dar de las cuatro clases, $y$ eso se llenó de todo eso, eso es un cuento indígena: el maíz encantao”. "Hay amarillo, rojo, blanco y marañoso o borreguito como un granzo".

\section{RECOLECCIÓN DE LA INFORMACIÓN}

\section{Técnicas}

Se realizó por medio de entrevistas con informantes clave. Según Martínez (1997), la misma consiste en formular preguntas sencillas con un diálogo coloquial, donde un entrevistador logrará que el entrevistado exprese sus experiencias y vivencias, en entrevistas cara a cara y dirigidas a la comprensión de sus vidas. Con la observación participativa se recaudó la información no verbal, comunicación de suma importancia para la investigación.

\section{Recursos}

Se utilizaron cámaras fotográficas para captar los momentos e imágenes más importantes, grabadores de audio para recoger la información suministrada por los informantes clave que es transcrita por los investigadores a fines de nutrir el análisis e interpretación del estudio; lápiz de grafito y papel en blanco para realizar las anotaciones correspondientes.

Aguirre (1997) enfoca la utilización de estos recursos como un objetivo de captar el lenguaje mímico, facial, no verbal, lo cual apoyará al interpretar posteriormente el lenguaje verbal. 
Es importante indicarle al entrevistado que los contenidos de la entrevista serán estrictamente confidenciales y sus fines sólo atenderán objetivos únicos y específicos de la investigación.

\section{EXPERIENCIAS ARTÍSTICAS CREATIVAS}

La majestuosidad de los bailes se expresan en cada son, distinto uno del otro, aunque presentan gran similitud en cuanto al ritmo musical, la mezcla del baile de tambores y flautas muy particulares hace del baile "Las Turas", una expresión singular. La transportación del Chamán de la etnia dentro del Palacio, regodea la mezcla de religión que ésta posee. La importancia que el mundo espiritual representa para los ayamanes es vívida presencia de su sentir, y el misterio que cubre y envuelve todos los rituales realizados durante el baile, constituyen oráculos de felicidad inminente.

\section{Majestuosidad del baile}

Significan el producto de un colorido no precisamente visual, sino espiritual, cuando se denotan colores. Las Turas conviven apegadas a la etnia ayamán y a todos sus ascendientes y descendientes. Se erige el baile como un alma grande que cobija pasado, presente y futuro de un pueblo y de todos los visitantes que deseen hacerlo suyo. Vibra la danza, los tambores con ellos, transitando caminos productivos, reconociéndose como arte y cultura..."como aquí representantes para que todos los invitaos y todos los organismos porque somos patrimonio cultural...," dice "La Reina, madre tierra”.

\section{Mezcla de Religión y Espiritualidad}

El Chamán mayor ya ascendido, el indio Paracatomi, protectores étnicos ayamanes, comunican el deseo de plegarias como promesas ofrecidas también por Mayordomos, Amos, Capataces, Reinas...”todos nosotros aquí”. La promesa es la de tocar un son de "Tura” para el Chamán antes del rosario, casi a la medianoche. Se le dan tres vueltas a la Capilla - entre música y tambores- “... y hacemos de aquí, lo llevamos derechito al Palacio Don Juan de Los Vientos y los espíritus se asocian en nuestros bailes para ayudarnos...”

Se alejan los miembros de la etnia al bosque para retirarse de los malos espíritus, santiguándose a sí mismos y a los demás con la marca de una cruz. Son espíritus de cortes indias, africanas y de diversos chamanes, atraídos para el cultivo de sus cosechas. Las risas, como un juego alegre cooperador, las melodías de aliento común cuando no bailan, es expresado verbalmente a quienes los visitan. En su altar además de maíz se observa la yuca, caña dulce, auyama, granos... Cuando reparten sus alimentos pregonan su abundancia y la pasión por la vida..., conversando, tarareando, bailando..., presencia de su sentir... donde los Chamanes dentro del Palacio representan la elevación espiritual más alta, ejemplo digno de alcanzar. Los rituales del baile se presentan dibujados claramente en los siete sones que se hacen realidad al momento de experimentarlos, tanto para la etnia como para los visitantes. Imaginación, datos peculiares, dones específicos son repartidos en estos rituales. Vibran los rezos... y poco a poco van llevando alimentos al altar mayor, se entrelazan las imágenes de sus santos que entre sueños y realidad vienen y van. Las comidas y bebidas sobrantes son llevadas al palacio, veneran la lluvia, el agua que es pura para el alma y se asemeja a ella. Los vuelos de los pájaros mueven sus vistas para reconocer algunos de ellos, así su fantasía hace gala a sus plegarias.

El sonido del alma que empuja sus "flautas-turas" significa la vida que les pertenece y a la que se rinden plenamente. El rito danzístico de manos agarradas es el trabajo de todos recogiendo verdades, caridad, amistad, confraternidad, comprensión, cordialidad, ternura y magia.

\section{ANÁLISIS DE LA INFORMACIÓN}


La categorización o clasificación para Perez (2001) exige una condición previa, de esfuerzo por parte del investigador, para sumergirse mentalmente en la realidad expresada. Este revisará los relatos escritos y oirá las grabaciones repetidamente, con la actitud de revivir la realidad en su situación concreta y, posteriormente, con la actitud de reflexionar acerca de la situación vivida para comprender lo que pasa.

La categorización realizada en esta investigación se detalla a continuación:

\section{Categorías}

\section{Tradición: \\ Estructura: \\ Identidad Religiosa: \\ Identidad con la Naturaleza: \\ Principios:}

\section{Subcategorías}

Identidad Cultural

Organización

Creencias

Conservación
Buenas costumbres

\section{Conceptualización de las categorías}

\section{Tradición:}

Se entiende como el conjunto de conocimientos, valores, creencias y cultura heredados por los ancestros de la etnia Ayamán y trasmitidos de una generación a otra.

\section{Estructura:}

Formas de ordenar todo lo relacionado con el baile "las Turas".

\section{Identidad Religiosa:}

Contenido espiritual envuelto en dioses, espíritus, ancestros y santos o seres como María Santísima.

\section{Identidad con la naturaleza:}

Significado y contacto de los ayamanes con su entorno natural y conservación de personas, especies vegetales y animales.

\section{Principios:}

Valores, respeto, dignidad, altruismo, creatividad y belleza otorgados por los ayamanes a todo lo que esté relacionado con sus bailes y normas de convivencia.

\section{Patrones y Dilemas}

\section{Patrones}

En la entrevista número uno se observan las siguientes frases:

(07)... "yo me vaya..."

(10)... "cuando yo me vaya..."

(28)... "a nuestros Dioses"

(31)... "a la cosecha y a nuestros Dioses"

(33)... "de los espíritus, el espíritus”

(35)... "es el espíritu mío"

(53)... "los sones..."

(56)... "sino sones"

(65)... "entre los sones..."

(86)..."cada son tiene su nombre..."

(87)... "siete sones..."

(88)... "el son de la ceremonia..."

(95)... "el nombre de un son..."

(121)... "el son de la hormiga..."

(176)... “el son variquí...”

(177)... "la chicha de maíz criollita..."

(178)... "el maíz y demás frutas...”

(179)... "las arepas son de maíz..."

(182)... "todo de maíz..."

(196)... “cuando el maíz está jojoto...” 
(121)... "el maíz era encantao..."

(214)... "el maíz marañoso...”

(175)... "el maíz fermentado..."

(108)... "vera ido a los bosques..."

(109)... "en los bosque...”"

(135)... "en el bosque..."

(109)... “oye llorío del agua..."

(111)... "pero hay el llorío del agua"

(126)... "en el brazo derecho..."

(128)... "porque el derecho tu sabio..."

(130)... "si por el lao derecho..."

(136)... “tenemos palacio ahí...”

(137)... "el palacio es como un altar..."

(144)... "si el instrumento..."

(145)... "son cinco instrumento..."

(157)... "ese de un carriso..."

(161)... "no eso es un carriso..."

(169)... "cuestiones indígenas el carato..."

(170)... "ahí el carato..."

(175)... "se hace el carato..."

(172)... "cubrir las cacerías..."

(78)... "cazadores con la cacerìa..."

En la entrevista número dos se encuentran los siguientes patrones:

(09) “en vano la unión...”

(14) "en la unión está la fuerza...”

(18)... "nuestro ancestro nos dejaron..."

(40)... "nuestro ancestro..."

(41)... "y a nuestro ancestro..."

(38)... “debiendo una promesa...”
(41)... “y debemos una promesa...”

(39)... "porque habemo cacao..."

(40)... "lo habemo sacao de la pena..."

(47)... "un son de tura..."

(48)... "ese son de tura..."

(58)... "si ese son..."

(59)... "el son de la cacería...”

(60)... " si no el son del encuentro..."

Se observan los siguientes patrones en la entrevista número tres de las siguientes líneas:

(08)... "el recibimiento de la sombra..."

(17)... "estamos la basura de la sombra..."

(20)... "donde bailamos la sombra..."

(25)... "dame a la sombra..."

(26)... "la sombra primero..."

(27)... "no baila la sombra..."

(08)... "la sombra y la cacería..."

(17)... "la cacería se coloca en el altar..."

(20)... "recibimiento de la sombra y la cacería..."

(21)... "la sombra estaba en mano..." 


\section{Dilemas}

En la entrevista número 1 y 2 se encuentran dilemas en cuanto a la religión de la etnia Ayamán, específicamente en las líneas 20,21,22,23 de la primera entrevista y 33,34 de la segunda entrevista.

20- La virgen María andaba con el niño

21- En brazo ya existía el baile

22- Las Turas por eso decimos el baile

23- de María Santísima

33-Que se le debía rezar un rosario

34- $\mathrm{Al}$ indio Paracatomi

34- Que es el protector de nosotros aquí.

\section{ANÁLISIS DE CONTENIDO}

De generación en generación la Capitana de "Las Turas”, señora María Perozo, hereda de su madre el título de Reina, que ha ejercido durante 14 años. Este trono pertenecerá posteriormente a su hija, y así traspasado posteriormente de madres a hijas. Se remonta el ritual de Las Turas, como inicialmente se conoce, desde tiempos de la antigüedad romana, desde cuando ya la virgen María cargaba al niño Jesús en sus brazos, y como inherente a la cultura tradicional del Cerro Moroturo. Sin embargo, en realidad, se inicia cuando la familia Perozo y todos sus ancestros se asientan en el lugar. De acuerdo a los episodios míticos de los primeros indígenas ayamanes reflejados en el baile, se desdibuja el nombre del baile, pero aún no tiene para esta época denominación determinada, lo cual se verifica en el hecho de que no mencionan dioses específicos, sino que dirigen sus plegarias, movimientos y episodios, a dioses universales y a espíritus de sus tribus y de comunidades cercanas.

En armonía con el espíritu propio, cada ayamán se reconoce a sí mismo como un ente físico y espiritual, valorando la existencia de ese "espíritu” y el de los demás. Reconoce y tiene la creencia de que cuando muera, su alma saldrá y ocupará el cuerpo de uno de los hijos de su descendencia, lo cual se repite como en un ciclo permitiendo que los ancestros siempre estén presentes en la tribu. A estos espíritus, el ayamán ofrece sus alimentos que según sus creencias son quienes les brindan sus frutos y la vida, para lo que seleccionan el día sábado, considerando que no sea un día de trabajo en el cual algunos de ellos o sus invitados estén ocupados en sus labores. Por lo general, seleccionan los últimos días de julio o septiembre, aunque pueden variar las fechas.

Durante la celebración invitan a los participantes a colaborar y a integrarse plenamente al baile, así, todos se toman de las manos en círculos, danzan cada son, experimentándolo intensamente, disfrutando de ellos, donde están prohibidas abiertamente, las críticas, las burlas, los comentarios y cualquier forma de conducta que no sea amena, placentera, de colaboración, apoyo mutuo, identidad, y sobre todo, como ellos lo recalcan, unidad.

Considerado ente colectivo, o un todo integrado, los pasos de los sones aunque repetitivos, son uniformes, y al unísono. De la misma manera, los sonidos y la música, pero más allá de esta perspectiva, el asombro y la emocionalidad se observan en la significancia de los sones porque cada uno es el reflejo de su ideosincracia, así como el contacto para ellos, muy intenso con la naturaleza, y sus detalles menudos. De allí surge la denominación de estos: el son de La Paloma, Hormiga, Murciélago, Turpial, Gonzalito, Chicharras. Los frutos como el maíz, caña, o frutas variadas, el colorido de su vegetación, el agua, y los animales vivos y de cacería, conforman elementos fundamentales de sus bailes, lo que representan en momentos, situaciones y conductas a ser favorecidas con su presencia, considerada muy sagrada y digna de respeto porque de lo contrario podría recibirse gran castigo de los espíritus.

Atender las horas de los sones también constituye un ritual, algunos comienzan a la cinco o seis de la tarde y hasta las siete de la mañana, los animales de cacería se reciben y se llevan a la gran Capilla, también las frutas que crecen en sus tierras, y las cosechas de otros plantíos. Los 
cazadores de animales son los que utilizarán las Turas grandes en el baile, en señal de que son los que han realizado mayor esfuerzo para traer mayor cantidad de alimentos a todos, y con ello mayor vivir. Un grupo de tureros cargando los instrumentos e interpretando el baile, se dirige a los cazadores que vienen en camino con los animales de cacería, todos se encuentran en el portal celebrando la caza con la música, luego es llevada a la Capilla donde le ofrendan y comienza el son que celebra la comida presente. Se realiza la ceremonia de repartición de alimentos actuando la Reina como miembro principal y conocedora fundamental de las tradiciones, historia y cultura del sagrado acto. Los sones tureros no representan solo música y connotación de tradiciones, leyendas, creencias, alegrías y celebración de los ayamanes; son vida y corazón del ayamán, es la mujer misma, el hombre, el niño-a, porque su identificación es plena con cada son, con cada significado del son, con cada detalle de la naturaleza que observa, y de su faena, todo lo cual desempeña con gran felicidad. Las escenas del agua corroboran estas afirmaciones. El título: "llorío del agua" contiene la impresión de un significado triste, pero cuando el agua cae a sus plantíos, se transforma en abundancia, riqueza material y plenitud de vida, se esconden las hormigas y cantan las chicharras en el inmenso bosque cargado de frutos. Ya al unísono, los pájaros marcan sus territorios anunciando un día soleado lleno de treguas, horizontes, además, de magia y ensueños de "variquí", este último como especie de porción para colocar cruces a las sombras traducidas en espíritus, como requisitos para poder formar parte del baile.

El tiempo y las horas recorridos por la etnia señalan su orden de vida, tienen demarcadas el día y la noche con exactitud y de acuerdo al tiempo, cada faena. Noches específicas suben la montaña hacia el altar, bailan turas $\mathrm{y}$ ofrecen lo sobrante de las comidas a sus santos y dioses. Con encantamientos y leyendas se comunican entre ellos durante los movimientos. Un Mayordomo se hace acompañar de ayudantes para realizar las faenas del maíz presentes en su baile ya como producto terminado para la cena general. El optimismo que se observa durante las comidas se verifica en la actitud hacia la preparación previa del baile. Esperan que asistan los organizadores incluyendo los de la otra etnia, y demuestran que están todos muy unidos. Cuando alguien no asiste envía a otra persona y la actividad prevista se realiza. Cumplen las promesas ofrecidas a sus santos Chamanes y oran a menudo antes de "Las Turas". Cuando muere alguno deberán tocar un son, caminan tres vueltas hacia la Capilla y lo llevan al Palacio Principal, el Capataz le da la bendición, continúan orando y lo despiden del mundo material para que sea recibido por sus ancestros.

Los sietes sones de "Las Turas" tienen un orden específico (descritos anteriormente). El son de la Sombra y Cacería también se llama Encuentro entre músicos y cazadores, finaliza cuando todos agradecen a la montaña. El son de La Sombra, significa ausencia de sol, que ha producido los frutos y el alimento en el pasado. Se ofrecen en la sombra alimentos recolectados para obtener muchos más. El resto de los sones parece sintetizarse en el son de La Sombra, momento final del baile, por cuanto como motivo repetitivo según la Reina, hay que tocar Turas amaneciendo porque llega la sombra al caserío por cortesía, y se baila en honor a ella. Al desmontar el altar, los bailadores toman la sombra para bailar con ella, en el mismo altar, tocando más son en ese momento. Al mismo tiempo las personas son marcadas con una cruz delante de la sombra para alejarlas de malos espíritus. En el son del variquí se bota la basura de la sombra, para recoger y traerse sólo el fruto de ésta.

Espíritu, realidad, fantasía, magia, poder personal o ancestral, idilios reales de una cultura contentiva de identidad religiosa propia, de tradición y sólidas creencias, con una estructura organizacional ayamánica, reconocida como valuarte, autóctona larense: "Los Ayamanes”, existen como pueblo y civilización, son "un territorio despierto”.

\section{REFERENCIAS}

Aguirre, B. (1997).Metodología cualitativa en la investigación sociocultural. Colombia: Alfaomega. 
$\begin{array}{cccc}\begin{array}{c}\text { Estrada, J. } \\ \text { indígenas.Documento }\end{array} \text { en } & \text { lines).Investigaciones } & \text { Etnográficas en poblaciones } \\ \text { Disponible: }\end{array}$ http://www.weblogs.madrimasd.orgHernan, J.(2005).Investigaciones Etnográficas. Documento en línea: Disponiblehttp://www. cgsm.gov.ar/detalle.php.

López, J. (2005). Etnología Americana. Documento en línea. Disponible:http/www.etnologiamericana.org/view/miembro.php.

Martínez, M. (1997). La investigación cualitativa etnográfica en educación. México: Trillas

Martínez, M. (2000). La investigación cualitativa etnográfica en educación. México: Trillas.

Martínez, M. (2004). Comportamiento humano. México: Trillas

Sandín Esteban, M.P (2003). Investigación cualitativa en educación. Fundamentos. España:Mc Graw Hill.

Perez, G. (2001).Investigación Cualitativa Retos e Interrogantes. Madrid: La Muralla. 
